MS48 Crystallography in art and cultural heritage from Czermno (Cherven Towns, eastern Poland) chemical analysis and metallurgical examination., Archeologia Polski, LX:2015, 123- 152

[2] A. Rafalska-Łasocha, M. Grzesiak-Nowak, D. Sarkowicz, W. Łasocha, The use of XRPD for the investigation of historic pigments and painting materials in works by Henryk Siemiradzki, J. Anal. At. Spectrom., 2015, 30, 751-758

Keywords: XRPD, cultural heritage, XRF
Chairs: Alicja Rafalska-Lasocha, Helen Stoeckli-Evans

\section{MS48-P2 X-ray powder diffractometry in the study of heritage objects from Polish museums \\ Alicja Rafalska-Lasocha ${ }^{1}$, Marta Grzesiak-Nowak ${ }^{1}$, Wiesław Łasocha $^{1,2}$}

1. Faculty of Chemistry Jagiellonian University, 30-060 Krakow, Ingardena 3, Poland

2. Jerzy Haber Institute of Catalysis and Surface Chemistry PAS, 30-239 Kraków, Niezapominajek 8, Poland

email: rafalska@chemia.uj.edu.pl

$\mathrm{X}$-ray-based techniques continue to be the preferred methods for scientific analysis of material composition of the objects of cultural heritage. Within this group, X-ray fluorescence (XRF) and X-ray powder diffraction (XRPD), due to their non-destructive nature, are the most popular and well-established methods in the field of heritage science. These scientific studies provide support for archaeologists, art historians, and conservators as they continue to expand their knowledge about heritage objects housed in museums and private collections. Information about the composition of heritage objects facilitates the understanding of historical events, manufacturing techniques, and provenance. In addition, the obtained results can assist in the formation of better preventive conservation strategies for the valuable ancient collections.

The XRF technique, usually applied as the first step of an investigation, provides information about the elemental composition of a sample, whereas XRPD enables identification of its phase composition. It is often difficult to identify the presence of a certain compound on the basis of XRF alone; thus, the results obtained by this technique usually require clarification or confirmation by XRPD.

Structure-oriented Powder Diffractometry group at the Faculty of Chemistry, Jagiellonian University, is involved in XRPD investigations of metallic archaeological objects (seals, coins, spearheads, jewellery) [1] and painting materials used by famous Polish painters [2] such as Henryk Siemiradzki, Aleksander Gierymski, Rafał Hadziewicz whose works are housed in a great number of museums. In our study we investigated works from the collections of the National Museum in Krakow. The obtained results and various case studies involving the use of XRPD will be presented with the aim of illustrating some of the possibilities and limitations encountered when analysing the objects of cultural heritage.

[1] M. Wołoszyn, E. M. Nosek, J. Stępiński, A. Rafalska-Łasocha, W. Łasocha, E. Bielańska, The seals 